\title{
Breathlessness and opioid prescribing in COPD in general practice: a cross- sectional, observational study
}

\author{
David C. Currow ${ }^{1,2}$, Miriam J. Johnson ${ }^{1,2}$, Allan Pollack ${ }^{3}$, Diana H. Ferreira ${ }^{4}$, \\ Slavica Kochovska ${ }^{1}$, Magnus Ekström ${ }^{5}$ and Christopher Harrison ${ }^{6}$
}

Affiliations: ${ }^{1}$ IMPACCT, Faculty of Health, University of Technology Sydney, Sydney, Australia. ${ }^{2}$ Wolfson Palliative Care Research Centre, University of Hull, Hull, England. ${ }^{3}$ Sydney School of Public Health, University of Sydney, Sydney, Australia. "Discipline Palliative and Supportive Services, Flinders University, Adelaide, Australia. ${ }^{5}$ Dept of Clinical Sciences, Division of Respiratory Medicine and Allergology, Lund University, Lund, Sweden. ${ }^{6}$ Menzies Centre for Health Policy, Sydney School of Public Health, University of Sydney, Sydney, Australia.

Correspondence: David C. Currow, Faculty of Health, University of Technology Sydney, P0 Box 123, Ultimo, New South Wales 2007, Australia. E-mail: david.currowauts.edu.au

ABSTRACT Chronic breathlessness is a disabling syndrome, prevalent in people with advanced chronic obstructive pulmonary disease (COPD). Regular, low-dose, oral sustained-release morphine is approved in Australia to reduce symptomatic chronic breathlessness. We aimed to determine the current prescribing patterns of opioids for chronic breathlessness in COPD in Australian general practice and to define any associated patient and practitioner characteristics.

Five years (2011 to 2016) of the Bettering the Evaluation and Care of Health database, an Australian national, continual, cross-sectional study of clinical care in general practice were used. The database included 100 consecutive clinical encounters from almost 1000 general practitioners annually ( $\mathrm{n}=488100$ encounters). Descriptive analyses with subsequent regression models were generated.

Breathlessness as a patient-defined reason for encounter was identified in 621 of 4522 encounters where COPD was managed. Opioids were prescribed in 309 of 4522 encounters where COPD was managed (6.8\%; (95\% CI) 6.1-7.6), of which only 17 were prescribed for breathlessness, and the rest for other conditions almost entirely related to pain. Patient age (45-64 years versus age $80+$ years, OR 1.68; 1.19-2.36), Commonwealth Concession Card holders (OR 1.70; 1.23-2.34) and socioeconomic disadvantage (OR 1.30; 1.01-1.68) were associated with increased likelihood of opioid prescription at COPD encounters. The rate of opioid prescriptions rose over the 5 years of study.

In primary care encounters for COPD, opioids were prescribed in $6.8 \%$ of cases, but almost never for breathlessness. These data create a baseline against which to compare changes in prescribing as the treatment of chronic breathlessness evolves.

@ERSpublications

In COPD, one in 13 people is prescribed opioids by family physicians in Australia, but rarely for chronic breathlessness https://bit.ly/2XO1Ol8

Cite this article as: Currow DC, Johnson MJ, Pollack A, et al. Breathlessness and opioid prescribing in COPD in general practice: a cross-sectional, observational study. ERJ Open Res 2020; 6: 002992019 [https://doi.org/10.1183/23120541.00299-2019]. 


\section{Introduction}

Chronic breathlessness is prevalent across the community, and is mainly related to self-reported respiratory diseases [1,2]. Chronic breathlessness syndrome, defined as disabling breathlessness which persists despite optimal treatment of the underlying pathophysiology [3], is associated with impaired physical and mental components of quality of life [4]. Primary care is the most common setting for both its initial presentation and ongoing clinical management [5-7].

The evidence base for the symptomatic reduction of chronic breathlessness has evolved over the last two decades. A key framework for the assessment and treatment of chronic breathlessness is the Canadian Thoracic Society ladder [8]. This approach includes reversing treatable causes, instigating evidence-based nonpharmacological interventions and, if appropriate, pharmacological interventions [9]. The pharmacological treatment with best evidence for the reduction of chronic breathlessness is regular, low-dose, sustained-release morphine $[10,11]$. The strongest evidence for its effectiveness is in people with severe breathlessness (modified Medical Research Council breathlessness scale 3 or 4 [12, 13]) and chronic obstructive pulmonary disease (COPD) [14].

The indication for sustained-release morphine (Kapanol) has recently (February 2019) been extended by the Australian Therapeutic Goods Administration to include "the symptomatic reduction of chronic breathlessness in the palliative care of patients with distressing breathlessness due to severe COPD, cardiac failure, malignancy or other cause. Kapanol should only be used after treatments for the underlying cause(s) of breathlessness have been optimised and nonpharmacological treatments are not effective" [15]. As this extended license may influence prescribing (both number of prescriptions and drug regimen used), it is timely to explore the baseline level of use of opioids for breathlessness in general practice.

General practice provides care for the largest number of people with chronic breathlessness [5-7]. These consultations result in an average of three medications being prescribed for each two consultations where breathlessness is the reported reason for encounter [5]. Given the approval noted above, knowledge about both the baseline level and the patterns of, until now, off-label prescribing of low-dose morphine for the symptomatic reduction of chronic breathlessness is important in the assessment of future patterns of prescribing.

The primary aim of this study was to define existing patterns of opioid prescribing over time for people with COPD and breathlessness in Australian general practice. Secondary aims included an exploration of patient or practitioner characteristics associated with opioid prescribing in people with COPD.

\section{Methods}

Design and setting

This study used data from the Bettering the Evaluation and Care of Health (BEACH) project, an Australian national, cross-sectional study of general practitioners' (GPs) clinical care [16]. The BEACH project collects data contemporaneously at the point of care on approximately 100000 nationally representative GP-patient encounters annually. Each year, a random sample of $1000 \mathrm{GPs}$ chosen from the Australian Government's Medicare claims records completed the project. Each GP recorded details of 100 consecutive encounters with consenting patients [17]. These details were recorded on structured paper forms wherever that encounter occurred (in the GP's consulting room or home visit, including residential aged care facilities) with each problem linked to the clinical actions undertaken by the GP. Data are representative of patient encounters with GPs in Australia [16]. The current study examines the last 5 years of BEACH data (April 2011 to March 2016 inclusive, when data collection for BEACH ceased) giving a total of almost 500000 encounters.

\section{Data}

Data were collected on the patient's own reported reasons for encounter, directly linked to problems/ diagnoses managed by the GP at the encounter, and consequent clinical actions: medications prescribed, supplied by the GP or advised for over-the-counter purchase; procedures undertaken; new referrals made; and any ordering of pathology or imaging investigations [16]. Demographic factors included sex, age and whether the person held a Commonwealth Concession Card. The latter includes aged pensioners, people receiving support for long-term disability and people who are unemployed. (In Australia, it is legal for medical practitioners to charge above the national insurance reimbursement. Practitioners are encouraged not to charge out-of-pocket payments for people who hold a Concession Card.)

Conditions were coded according to the International Classification of Primary Care version 2 PLUS (ICPC-2 PLUS) by trained coders and automatically classified to ICPC-2 [18, 19]. Medications were coded using the Coding Atlas of Pharmaceutical Substances [20], and automatically classified to the Anatomical Therapeutic Chemical classification [21]. GPs could record the name of the medication, strength, regimen 
and number of repeats. They could also indicate whether this was a new or continuing prescription. To ensure opioid doses were comparable, oral morphine equivalent doses were calculated for all prescribed opioids using a single resource [22].

\section{Population and time period}

We analysed all encounters in the last 5 years of BEACH data collection (April 2011 to March 2016 inclusive) where COPD was recorded as a problem managed at encounter. We made no distinction between first presentation of COPD and COPD that had been managed previously.

COPD was defined as ICPC-2 rubric R95 “Chronic Obstructive Pulmonary Disease" [18, 19]. A secondary interest was to see whether a patient presented with breathlessness as a reason for encounter (i.e. in the patient's own words). Breathlessness was defined as ICPC-2 rubric R02 "Shortness of Breath/Dyspnoea" [18, 19]. Opioids were defined as Anatomical Therapeutic Chemical code N02A "Opioids" [21]. A low dose of opioid was defined as an oral morphine equivalent prescribed daily dose (OMEPDD) of $\leqslant 30 \mathrm{mg}$ [21].

For encounters where COPD was managed, we examined whether opioids were prescribed directly for the management of COPD or for problems unrelated to COPD (with ICPC codes other than those included in R95). We also examined whether opioid prescribing was different for patients who had breathlessness as a stated reason for encounter.

We were able to determine the patient's relative level of socioeconomic advantage using Socio-Economic Indexes for Areas (SEIFA) Index of Relative Socio-Economic Advantage and Disadvantage (IRSAD) [23] based on their residential postcode. A patient was considered to be from a non-English-speaking background if they reported that they spoke a language other than English as their primary language at home. A person's Aboriginal or Torres Strait Islander status ("Indigenous") was determined by self-report. The remoteness of each general practice was determined by the Australian Statistical Geography Standard [24].

\section{Statistical analyses}

No data were imputed. COPD management rate was examined by patient and GP characteristics. We compared the opioids prescribed at COPD encounters by those prescribed for the direct management of COPD to those prescribed for the management of other non-COPD problems also managed at the COPD encounter. The proportion of COPD encounters at which an opioid was prescribed was examined by GP and patient characteristics at the univariate level. To determine which patient and GP characteristics were independently associated with opioid prescribing at COPD encounters, a multivariate logistic regression was performed with backwards elimination until a parsimonious model was achieved.

Analyses were adjusted for the cluster survey design (100 encounters for each GP) All analyses were conducted using SAS 9.4 (SAS Institute Inc., Cary, NC, USA). Given multiple comparisons, differences between point estimates were considered statistically significant if their 95\% CIs were not overlapping (equivalent to $\mathrm{p}<0.006$ ).

\section{Ethics and consent}

The BEACH research program was approved by the Human Research Ethics Committee of the University of Sydney (2012/130). Only aggregated, de-identified data are presented.

\section{Results}

Proportion of COPD-related management at general practice encounters

Of 488100 encounters, $4522(0.93 \%)$ had COPD recorded by the GP as one of the problems managed. (table 1) The proportion of COPD-related encounters was higher among patients who were male; older; holding a Commonwealth Concession Card; from an English-speaking background; from a more socioeconomically disadvantaged area; Indigenous; and known to that GP's practice. The proportion of patients managed with COPD was higher in encounters with GPs who themselves were: male; older; and/ or working in nonmajor city practices.

\section{Opioid prescribing at COPD encounters}

Of the 4522 encounters where COPD was managed, opioids were prescribed at 309 (6.8\%), with 377 prescriptions being written. (table 2 and figure 1) Of the 4522 COPD problems managed, at least one opioid was prescribed directly for its management on 17 occasions, or $0.38 \%$ of the times COPD was managed. Of the 377 opioid prescriptions at COPD encounters, only 23 (6.1\%) were for the direct management of COPD, whereas 354 (93.9\%) were for other (non-COPD) problems. Of the 23 opioid prescriptions for COPD, $18(78.3 \%)$ were for morphine, whereas morphine comprised only $8.8 \%$ of the 354 opioids prescribed for non-COPD-related problems. We were only able to calculate an OMEPDD for 10 of the 23 opioid prescriptions prescribed for COPD, of which 80\% were low dose. Of the 354 


\begin{tabular}{|c|c|c|c|}
\hline Characteristics & $\begin{array}{c}\text { Encounters where COPD } \\
\text { managed } \\
n=4522\end{array}$ & $\begin{array}{l}\text { Encounters in } \\
\text { sample } \\
n=488100\end{array}$ & $\begin{array}{l}\text { Proportion of encounters } \\
\text { where COPD managed }\end{array}$ \\
\hline \multicolumn{4}{|l|}{ Patient characteristics } \\
\hline \multicolumn{4}{|l|}{ Sex } \\
\hline Male & 2279 & 195991 & $1.16 \%(1.10-1.22)$ \\
\hline Female & 2205 & 287848 & $0.77 \%(0.73-0.81)$ \\
\hline \multicolumn{4}{|l|}{ Age } \\
\hline$<25$ years & 7 & 94364 & $0.01 \%(0.00-0.01)$ \\
\hline 25-44 years & 110 & 107575 & $0.10 \%(0.08-0.12)$ \\
\hline 45-64 years & 1052 & 132027 & $0.80 \%(0.74-0.85)$ \\
\hline $65-79$ years & 2140 & 98142 & $2.18 \%(2.07-2.29)$ \\
\hline $80+$ years & 1181 & 51846 & $2.28 \%(2.13-2.43)$ \\
\hline \multicolumn{4}{|c|}{ Commonwealth Concession Card } \\
\hline Yes & 3446 & 200495 & $1.72 \%(1.65-1.79)$ \\
\hline No & 841 & 246429 & $0.34 \%(0.31-0.37)$ \\
\hline \multicolumn{4}{|c|}{ Language background } \\
\hline English & 4002 & 400671 & $1.00 \%(0.96-1.04)$ \\
\hline Other language & 258 & 38901 & $0.66 \%(0.57-0.75)$ \\
\hline \multicolumn{4}{|c|}{ Socioeconomic status } \\
\hline Advantaged & 2006 & 288605 & $0.70 \%(0.66-0.73)$ \\
\hline Disadvantaged & 2425 & 189031 & $1.28 \%(1.21-1.35)$ \\
\hline \multicolumn{4}{|l|}{ Indigenous status } \\
\hline Indigenous & 119 & 8820 & $1.35 \%(1.07-1.63)$ \\
\hline Non-indigenous & 4145 & 430863 & $0.96 \%(0.92-1.00)$ \\
\hline \multicolumn{4}{|c|}{ Patient new to practice } \\
\hline Yes & 136 & 36470 & $0.37 \%(0.31-0.44)$ \\
\hline No & 4316 & 444368 & $0.97 \%(0.93-1.01)$ \\
\hline \multicolumn{4}{|c|}{ GP characteristics and clinical practice factors } \\
\hline \multicolumn{4}{|c|}{ Sex } \\
\hline Male & 2883 & 278700 & $1.03 \%(0.98-1.09)$ \\
\hline Female & 1639 & 209400 & $0.78 \%(0.73-0.84)$ \\
\hline \multicolumn{4}{|l|}{ Age } \\
\hline$<45$ years & 920 & 128300 & $0.72 \%(0.66-0.78)$ \\
\hline $45-54$ years & 1240 & 143000 & $0.87 \%(0.80-0.93)$ \\
\hline $55+$ years & 2342 & 213900 & $1.09 \%(1.03-1.16)$ \\
\hline \multicolumn{4}{|l|}{ Practice location } \\
\hline Major city & 2703 & 343500 & $0.79 \%(0.75-0.83)$ \\
\hline Inner regional & 1226 & 95800 & $1.28 \%(1.18-1.38)$ \\
\hline $\begin{array}{l}\text { Outer regional/ } \\
\text { remote }\end{array}$ & 585 & 47500 & $1.23 \%(1.09-1.37)$ \\
\hline \multicolumn{4}{|c|}{ Country of graduation } \\
\hline Australia & 3097 & 323100 & $0.96 \%(0.91-1.01)$ \\
\hline Overseas & 1411 & 163300 & $0.86 \%(0.80-0.92)$ \\
\hline \multicolumn{4}{|l|}{ Fellow of a college $\#$} \\
\hline Yes & 2709 & 303100 & $0.89 \%(0.85-0.94)$ \\
\hline No & 1773 & 180500 & $0.98 \%(0.92-1.04)$ \\
\hline Total & 4522 & 488100 & $0.93 \%(0.89-0.96)$ \\
\hline \multicolumn{4}{|c|}{$\begin{array}{l}\text { Data are presented as } \mathrm{n} \text { or } \%(95 \% \mathrm{CI}) \text {. \#: Fellow of either the Royal Australian College of GPs or the } \\
\text { Australian College of Rural Remote Medicine. All GPs in Australia have to do a post-graduate Fellowship in } \\
\text { order to be registered to practice. This training deals with frequently encountered conditions such as } \\
\text { COPD. All GPs must participate in continuing professional education, although the topics are at the } \\
\text { discretion of GPs. }\end{array}$} \\
\hline
\end{tabular}

prescriptions for non-COPD-related problems, an OMEPDD was calculable for 252, of which 51\% were low dose. The proportion of encounters at which an opioid was prescribed for COPD increased over the 5 years of data together with the proportion for COPD encounters, and opioid prescriptions for non-COPD problems (figure 2). 


\begin{tabular}{|c|c|c|}
\hline \multirow[t]{2}{*}{ Opioid prescribed } & \multicolumn{2}{|c|}{$\begin{array}{l}\text { Number of opioid prescriptions } \\
\qquad N=377\end{array}$} \\
\hline & $\begin{array}{l}\text { Prescription for non-COPD } \\
\text { condition } \\
n=354\end{array}$ & $\begin{array}{l}\text { Prescription directly for } \\
\text { COPD management } \\
n=23\end{array}$ \\
\hline Morphine & $31(8.8 \%)$ & $18(78.3 \%)$ \\
\hline Oxycodone & $93(26.3 \%)$ & $1(4.3 \%)$ \\
\hline Oxycodone and naloxone & $19(5.4 \%)$ & $1(4.3 \%)$ \\
\hline Hydromorphone & $9(2.5 \%)$ & \\
\hline Codeine $^{\#}$ & $74(20.9 \%)$ & $1(4.3 \%)$ \\
\hline Fentanyl & $20(5.6 \%)$ & \\
\hline Buprenorphine & $60(16.9 \%)$ & $2(8.7 \%)$ \\
\hline Tramadol & $38(10.7 \%)$ & \\
\hline Tapentadol & $2(0.6 \%)$ & \\
\hline Other & $8(2.3 \%)$ & \\
\hline
\end{tabular}

Data are presented as $\mathrm{n}(\%)$. At the 309 encounters where COPD was managed, there were 312 problems generating 377 opioid prescriptions: 354 prescriptions for 295 non-COPD problems; and 23 prescriptions for 17 COPD-related problems. ${ }^{\#}$ : alone or in combination.

When an opioid was prescribed at a COPD encounter pain was the most common indication for its prescription the three most prevalent clinical indications being back pain $(25.0 \%$ of problems), osteoarthritis (17.6\%) and pain (general or multiple sites; $13.1 \%$ ).

Breathlessness was stated as a patient-described reason for encounter in only 621 of 4522 (13.7\%) of those managed for an encounter for COPD, and 37 of 309 (12.0\%) in patients with an encounter for COPD managed with opioids. At COPD encounters with an opioid prescription for a COPD-related problem, pain was still the most common reason for prescription. However, those people who gave breathlessness as

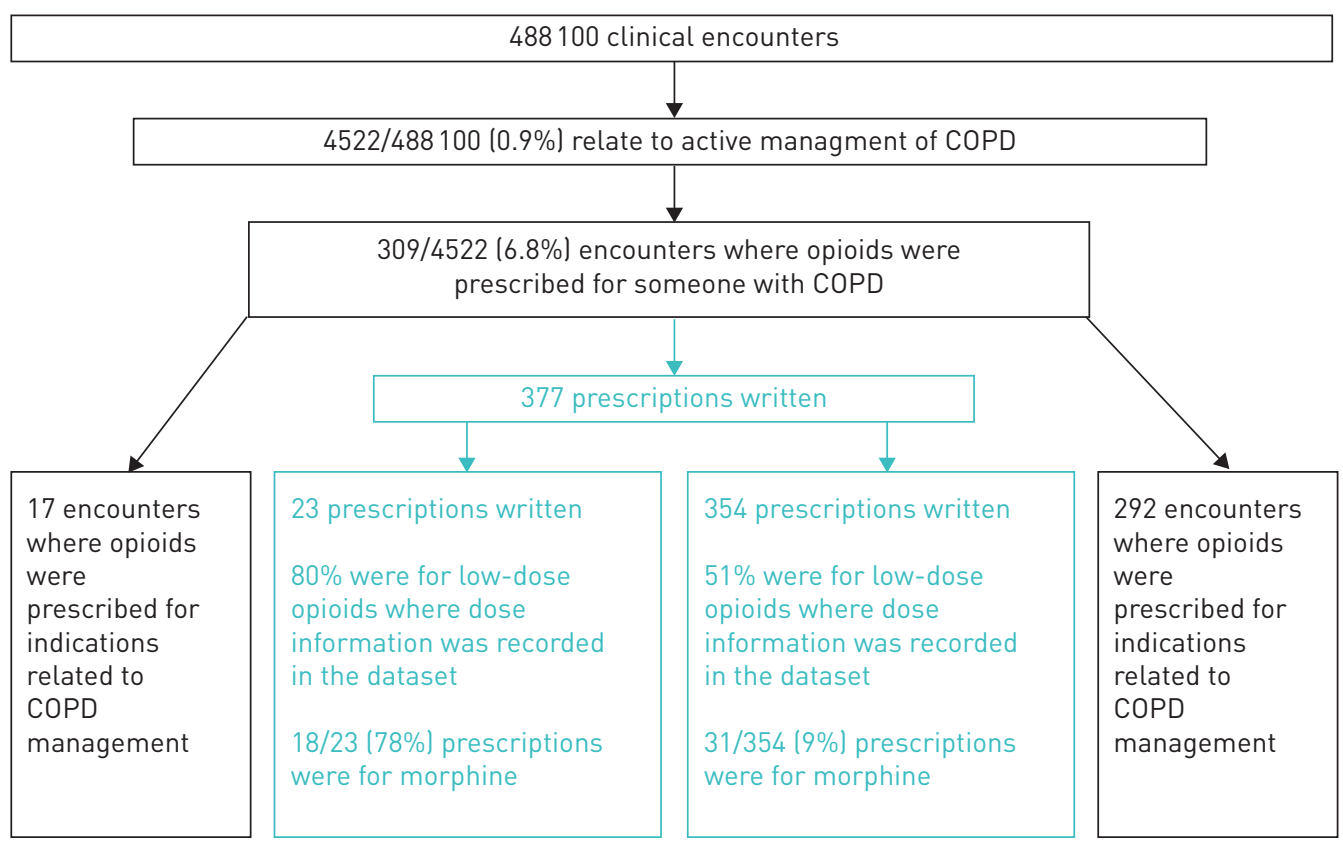

FIGURE 1 Flow diagram of a representative sample of Australian general practice adult consultations relating to opioid prescribing in people with COPD. 


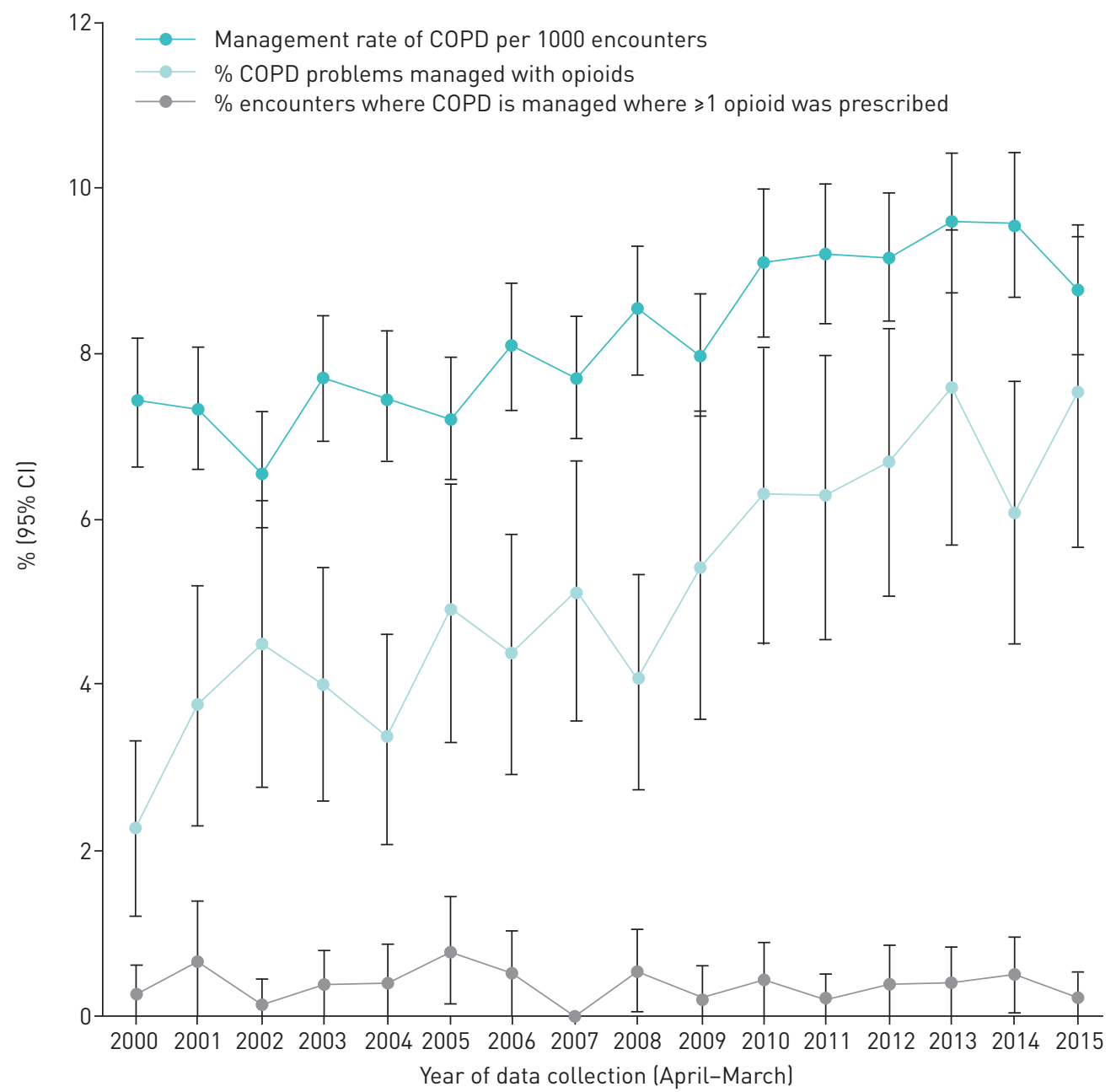

FIGURE 2 The proportion of encounters in which COPD was managed and the encounters at which an opioid was prescribed for COPD or non-COPD-related problems.

a reason for encounter were no more likely to be prescribed opioids than the rest of the population with COPD. (table 3)

\section{Unadjusted univariate predictors of opioid prescription}

Commonwealth Concession cardholders were more likely to be prescribed opioids $(7.46 \%$ compared to $4.40 \%$ for those without a Concession card) (table 3). Otherwise there were no unadjusted univariate significant differences in the likelihood of opioid prescription by patient characteristic (sex, age, language background, socioeconomic or Indigenous status, or whether they were new to the practice), by GP characteristic (sex, age, country of medical graduation or location of practice) or by the presence or absence of breathlessness as a reason for encounter.

\section{Multivariate logistic regression}

All patient and GP characteristics reported in the univariate analyses were included in a multivariate analysis. After backwards elimination, the final parsimonious multivariate logistic regression model found that a patient holding a Commonwealth Concession Card, living in a more socioeconomically disadvantaged area or being aged 45-64 years were all independently associated with an increased likelihood of opioid prescription at COPD encounters (table 4).

\section{Discussion}

Nearly $1 \%$ of all GP encounters were related to COPD. However, only a small proportion (6.8\%) of these were prescribed opioids at these encounters. Almost all opioid prescriptions at COPD encounters were for the management of non-COPD problems, mostly pain. Although a range of opioids (mainly oxycodone) 


\begin{tabular}{|c|c|c|c|c|}
\hline & $\begin{array}{l}\text { People managed for } \\
\text { COPD-related } \\
\text { problems } \\
n=4522\end{array}$ & $\begin{array}{l}\text { Point estimate for } \\
\text { people prescribed } \\
\text { opioids } \\
n=309(\%)\end{array}$ & $\begin{array}{l}\text { Lower } \\
95 \% \mathrm{Cl}\end{array}$ & $\begin{array}{l}\text { Upper } \\
95 \% \mathrm{Cl}\end{array}$ \\
\hline \multicolumn{5}{|l|}{$\begin{array}{l}\text { Patient characteristics in } \\
\text { those with COPD }\end{array}$} \\
\hline \multirow[t]{2}{*}{ Sex } & Male (2279) & $6.32 \%$ & $5.25 \%$ & $7.39 \%$ \\
\hline & Female (2205) & $7.44 \%$ & $6.29 \%$ & $8.58 \%$ \\
\hline \multirow[t]{4}{*}{ Age } & $<45$ years (117) & $6.84 \%$ & $2.28 \%$ & $11.40 \%$ \\
\hline & $45-64(1052)$ & $8.46 \%$ & $6.77 \%$ & $10.15 \%$ \\
\hline & $65-79(2140)$ & $6.82 \%$ & $5.67 \%$ & $7.97 \%$ \\
\hline & $80+(1181)$ & $5.50 \%$ & $4.19 \%$ & $6.82 \%$ \\
\hline \multirow{2}{*}{$\begin{array}{l}\text { Commonwealth } \\
\text { Concession Card }\end{array}$} & Yes (3446) & $7.46 \%$ & $6.52 \%$ & $8.40 \%$ \\
\hline & No $(841)$ & $4.40 \%$ & $3.02 \%$ & $5.78 \%$ \\
\hline \multirow[t]{2}{*}{ Socioeconomic status } & Less advantaged (2425) & $5.78 \%$ & $4.72 \%$ & $6.85 \%$ \\
\hline & More advantaged (2006) & $7.84 \%$ & $6.68 \%$ & $8.99 \%$ \\
\hline \multirow[t]{2}{*}{ Language background } & English (4002) & $5.04 \%$ & $2.43 \%$ & $7.65 \%$ \\
\hline & $\begin{array}{l}\text { Non-English speaking } \\
\text { (258) }\end{array}$ & $6.95 \%$ & $6.10 \%$ & $7.79 \%$ \\
\hline \multirow{2}{*}{$\begin{array}{l}\text { Aboriginal or Torres } \\
\text { Strait Islander status }\end{array}$} & No $(4145)$ & $6.90 \%$ & $6.07 \%$ & $7.73 \%$ \\
\hline & Yes (119) & $4.20 \%$ & $0.62 \%$ & $7.78 \%$ \\
\hline \multirow{2}{*}{$\begin{array}{l}\text { Patient new to the } \\
\text { practitioner }\end{array}$} & No (4316) & $6.88 \%$ & $6.08 \%$ & $7.69 \%$ \\
\hline & Yes (136) & $5.15 \%$ & $1.49 \%$ & $8.80 \%$ \\
\hline \multicolumn{5}{|c|}{ GP prescriber characteristics } \\
\hline \multirow[t]{2}{*}{ Sex } & Male (2883) & $6.69 \%$ & $5.71 \%$ & $7.68 \%$ \\
\hline & Female (1639) & $7.08 \%$ & $5.80 \%$ & $8.36 \%$ \\
\hline \multirow[t]{3}{*}{ Age } & $<45(920)$ & $6.52 \%$ & $4.86 \%$ & $8.18 \%$ \\
\hline & $45-54(1240)$ & $7.34 \%$ & $5.90 \%$ & $8.78 \%$ \\
\hline & $55+(2342)$ & $6.75 \%$ & $5.62 \%$ & $7.87 \%$ \\
\hline \multirow{2}{*}{$\begin{array}{l}\text { Primary medical } \\
\text { degree }\end{array}$} & Australia (3097) & $6.97 \%$ & $6.02 \%$ & $7.93 \%$ \\
\hline & Elsewhere (1411) & $6.59 \%$ & $5.21 \%$ & $7.97 \%$ \\
\hline \multirow{2}{*}{ Fellow of the College } & Yes (2709) & $6.61 \%$ & $5.65 \%$ & $7.57 \%$ \\
\hline & No (1773) & $7.22 \%$ & $5.88 \%$ & $8.56 \%$ \\
\hline \multirow[t]{3}{*}{ Place of practice } & Major city (2703) & $6.36 \%$ & $5.40 \%$ & $7.33 \%$ \\
\hline & Inner regional (1226) & $7.18 \%$ & $5.61 \%$ & $8.75 \%$ \\
\hline & $\begin{array}{l}\text { Outer regional/rural/ } \\
\text { remote (585) }\end{array}$ & $8.38 \%$ & $5.96 \%$ & $10.79 \%$ \\
\hline \multicolumn{5}{|l|}{ Clinical } \\
\hline \multirow{2}{*}{$\begin{array}{l}\text { Breathlessness as the } \\
\text { reason for encounter }\end{array}$} & Yes (621) & $5.96 \%$ & $4.06 \%$ & $7.86 \%$ \\
\hline & No (3901) & $6.97 \%$ & $6.12 \%$ & $7.83 \%$ \\
\hline \multicolumn{2}{|l|}{ Total $n=309$} & $6.83 \%$ & $6.05 \%$ & $7.62 \%$ \\
\hline
\end{tabular}

was prescribed for non-COPD-related problems, the most common opioid prescribed for COPD was morphine. The rate of opioid prescriptions rose over the 5 years of study.

As a descriptive study, it can only define associations. Associations were seen with COPD and socioeconomic status, explained almost entirely by differential smoking rates by socioeconomic status. In Australia, these vary by 2.5 -fold from the highest to the lowest socioeconomic quintiles. Likewise, it is not surprising to see demographic differences in GPs' encounters for people with COPD, given that many patients age along with their GPs.

This study adds a level of detail not possible from previous large prescribing studies. Vozonis et al. [25] reported on the outcomes for 130000 people with COPD who were prescribed opioids. The reason for the prescription was unavailable in that dataset. This study identifies that the overwhelming majority of opioid prescriptions in consultations involving management of COPD were given for other pain-related problems. Our data provide the reason for encounter linked to GP's clinical management including the very small proportion who had symptomatic treatment of breathlessness. This may reflect previous reports of poor GP confidence in managing the symptom of breathlessness [26]. 


\begin{tabular}{|c|c|c|c|c|c|}
\hline & \multirow[t]{2}{*}{ Domain } & \multirow[t]{2}{*}{ Subgroup } & \multicolumn{3}{|c|}{ Odds ratio estimates } \\
\hline & & & $\begin{array}{c}\text { Point } \\
\text { estimate }\end{array}$ & $\begin{array}{l}\text { Lower } \\
95 \% \mathrm{Cl}\end{array}$ & $\begin{array}{l}\text { Upper } \\
95 \% \mathrm{Cl}\end{array}$ \\
\hline \multirow{8}{*}{$\begin{array}{l}\text { Patient } \\
\text { characteristics }\end{array}$} & \multirow[t]{4}{*}{ Age (years) } & $80+$ (reference) & 1.000 & & \\
\hline & & $65-79$ & 1.21 & 0.90 & 1.65 \\
\hline & & $45-64$ & 1.68 & 1.19 & 2.36 \\
\hline & & $25-44$ & 1.39 & 0.64 & 3.02 \\
\hline & \multirow{4}{*}{$\begin{array}{l}\text { Commonwealth Concession } \\
\text { Card holder } \\
\text { Socioeconomic status }\end{array}$} & No (reference) & 1.000 & & \\
\hline & & Yes & 1.70 & 1.23 & 2.34 \\
\hline & & $\begin{array}{l}\text { More advantaged } \\
\text { (reference) }\end{array}$ & & 1.000 & \\
\hline & & Less advantaged & 1.30 & 1.01 & 1.68 \\
\hline
\end{tabular}

This study covers a period of clinical research where the evidence base for the symptomatic treatment of chronic breathlessness has evolved rapidly. During the study period several meta-analyses have been published that help establish a role for regular, low-dose morphine to reduce the intensity of chronic breathlessness [11, 27]. In response to this growing evidence base, there is now a world's first registration for any medication for the symptomatic reduction of chronic breathlessness [28]. As such, this background rate of prescribing opioids in the presence of breathlessness as the reason for encounter forms an important baseline against which to evaluate future changes in general practice prescribing.

A longitudinal cohort study in Australia reported that people who were prescribed opioid analgesics for persistent noncancer pain are less likely to have private health insurance [29]. Our study results correlate with those findings. The higher opioid prescription rates for people living in more socially disadvantaged areas reflects trends for opioid prescription in people with persistent noncancer pain in Australia [29].

\section{Strengths}

The major strengths of this study are the large number of clinical consultations drawn from a representative sample of GPs nationally, the coverage of clinical settings included and the quality of the clinical and demographic information associated with the prescription of opioids. The use of a consecutive cohort limits selection bias.

\section{Limitations}

This study provides cross-sectional data with no further information on the short- or long-term clinical outcomes from each consultation. This is in contrast to one previous, registry-based study, where long-term outcomes, including hospitalisations and mortality, were defined by lower- versus higher-dose opioids in people with oxygen-dependent COPD and, separately, oxygen-dependent interstitial lung disease [9, 30]. The assessment of chronic breathlessness seeking reversible causes and the use of nonpharmacological interventions are beyond the scope of the dataset [8,31]. If patients had multiple problems, it is possible that they may not identify chronic breathlessness at every encounter, potentially under-estimating the population of patients in contact with GPs who experience the syndrome.

Application of these findings to other health systems depends on the roles, costs, accessibility and relationships between primary, secondary and tertiary care. This study was performed in a country with universal health insurance for permanent residents, with a strong specialist workforce.

\section{Implications for clinical care}

Given population rates of modified Medical Research Council 3 or 4 of about 1\% [1] and the burden of disability that chronic breathlessness brings, rates of opioid prescriptions may rise in the coming years with a world first approval for regular, low-dose, sustained-release morphine for the symptomatic reduction of chronic breathlessness. As the evidence base is derived only from people with advanced, progressive diseases and severe chronic breathlessness mainly in tertiary care settings, prescribing in primary care needs to be followed carefully in pharmacovigilance studies (using these current data as a baseline) to understand the longer term net effects (i.e. benefits and harms). Further, broadening data collection to ensure reversible causes contributing to breathlessness have been addressed systematically and 
that evidence-based, nonpharmacological interventions have been employed will help to optimise clinical outcomes $[8,31]$.

The other fundamental challenge highlighted by these data is that either people with COPD appear not to seek help for chronic breathlessness, or if they do, there is no clinical response, or, this is not seen as sufficiently clinically relevant to be documented by the clinician. Only $13.7 \%$ (621 of 4255) of people with COPD had breathlessness documented as a reason for encounter. A proportion of the patients whose care is reflected in this study will have chronic breathlessness that will cause ongoing limitations in activities in daily living $[32,33]$. Despite increased evidence for the symptomatic treatment of chronic breathlessness, pessimistic expectations of both the patient and the clinician may engender a degree of therapeutic nihilism. A recent observational cohort examining the prevalence chronic breathlessness in people with COPD found that 53\% had persistent disabling breathlessness despite optimal treatment, yet few or no interventions had been documented [34]. This is consistent with another study highlighting that further management of chronic breathlessness is not regarded as necessary [35]. Our study, again, highlights the need for clinicians to appropriately diagnose chronic breathlessness and record its effect on the patient.

\section{Implications for future research}

This study creates an objective baseline for the prescription of opioids for the management of COPD. Following trends in prescribing by using an identical methodology will be important for the future assessment of the evidence for the use of regular, low-dose, sustained-release morphine for the symptomatic reduction of chronic breathlessness.

Acknowledgements: We thank Helena Britt (University of Sydney, Sydney, Australia) for her very helpful review of the manuscript and for being such a diligent steward of the dataset since its inception. We also thank Debbie Marriott (University of Technology Sydney, Sydney, Australia) for her patient help in preparing the manuscript.

Conflict of interest: D.C. Currow reports that he is an unpaid advisory board member for Helsinn Pharmaceuticals. He is a paid consultant and receives payment for intellectual property with Mayne Pharma and is a consultant with Specialised Therapeutics Australia Pty. Ltd. M.J. Johnson has nothing to disclose. A. Pollack has nothing to disclose. D.H. Ferreira has nothing to disclose. S. Kochovska has nothing to disclose. M. Ekström has nothing to disclose. C. Harrison has nothing to disclose.

Support statement: This study was funded by discretionary funds held by the research team at IMPACCT (Improving Palliative, Aged and Chronic Care through Research and Clinical Translation), University of Technology Sydney.

Funding BEACH supporting organisations 2000-2016 include: Australian Government Department of Health (1998-2004, 2007-2016); AstraZeneca Pty Ltd. (Australia) (1998-2016); Seqirus Australia) Pty Ltd. (2010-2016); Sanofi-Aventis Australia Pty Ltd. (2006-2012, 2015-16); AbbVie Pty Ltd. (2014-2015); Merck, Sharp and Dohme (Australia) Pty Ltd. (2002-2013); Pfizer Australia (2003-2013); National Prescribing Service Ltd. (2005-2009, 2012-2013); GlaxoSmithKline Australia Pty Ltd. (2010-2012); Bayer Australia Ltd. (2010-2011); Janssen-Cilag Pty Ltd. (2000-2010); Abbott Australasia Pty Ltd. (2006-2010); Wyeth Australia Pty Ltd. (2008-2010); Roche Products Pty Ltd. (1998-2006).

Funders had no role in any part of the study design, execution, interpretation nor in any decisions about publication nor dissemination. This funding was not associated with nor given to any of the authors. Funding information for this article has been deposited with the Crossref Funder Registry.

\section{References}

1 Currow DC, Plummer J, Crockett A, et al. A community population survey of prevalence and severity of dyspnoea in adults. J Pain Symptom Manage 2009; 38: 533-545.

2 Johnson M, Bowden J, Abernethy AP, et al. To what causes do people attribute their chronic breathlessness? A population survey. J Palliat Med 2012; 15: 744-750.

3 Johnson MJ, Yorke J, Hansen-Flaschen J, et al. Towards an expert consensus to delineate a clinical syndrome of chronic breathlessness. Eur Resp J 2017; 49: 1602277.

4 Currow DC, Dal Grande E, Ferreira D, et al. Chronic breathlessness associated with poorer physical and mental health-related quality of life (SF-12) across all adult age groups. Thorax 2017; 72: 1151-1153.

5 Currow DC, Clark K, Mitchell GK, et al. Prospectively collected characteristics of adult patients, their consultations and outcomes as they report breathlessness when presenting to general practice in Australia. PLoS ONE 2013; 8: e74814.

6 Frese T, Sobeck C, Herrmann K, et al. Dyspnea as the reason for encounter in general practice. J Clin Med Res 2011; 3: 239-246.

7 von Winckelmann K, Renier W, Thompson M, et al. The frequency and outcome of acute dyspnoea in primary care: an observational study. Eur J Gen Pract 2016; 22: 240-246.

8 Marciniuk DD, Goodridge D, Hernandez P, et al. Canadian Thoracic Society COPD Committee Dyspnea Expert Working Group. Managing dyspnea in patients with advanced chronic obstructive pulmonary disease: a Canadian Thoracic Society clinical practice guideline. Can Respir J 2011; 18: 69-78.

9 Ekström M, Abernethy AP, Currow DC. The management of chronic breathlessness in patients with advanced and terminal illness. Br Med J 2015; 349: g7617.

10 Ekström M, Bajwah S, Bland JM, et al. One evidence base; three stories: do opioids relieve chronic breathlessness? Thorax 2018; 73: 88-90. 
11 Ekström M, Nilsson F, Abernethy AP, et al. Effects of opioids on breathlessness and exercise capacity in chronic obstructive pulmonary disease. A systematic review. Ann Am Thoracic Soc 2015; 12: 1079-1092.

12 Bestall JC, Paul E, Garrod R, et al. Usefulness of the Medical Research Council (MRC) dyspnoea scale as a measure of disability in patients with chronic obstructive pulmonary disease. Thorax 1999; 54: 581-586.

13 Fletcher CM. Standardised questionnaire on respiratory symptoms: a statement prepared and approved by the MRC Committee on the Aetiology of Chronic Bronchitis (MRC breathlessness score). BMJ 1960; 2: 1665.

14 Currow DC, Louw S, McCloud P, et al. Regular, sustained release morphine for chronic breathlessness: a multi-centre, double-blind, randomised, placebo-controlled trial. Thorax 2019; 75: 50-56.

15 Therapeutic Goods Administration, Public Summary: KAPANOL morphine sulfate pentahydrate $10 \mathrm{mg}$ capsule blister pack. Commonwealth of Australia, 2019.

16 Britt H, Miller GC, Henderson J, et al. General Practice Activity in Australia 2015-16. Sydney, Sydney University Press, 2016.

17 Britt H. BEACH-Bettering the Evaluation and Care of Health: a continuous national study of general practice activity. Commun Dis Intell Q Rep 2003; 27: 391-393.

18 Family Medicine Research Centre TUoS. ICPC-2 PLUS: BEACH Coding System. 2002-2019. https://sydney.edu. $\mathrm{au} /$ medicine/fmrc/icpc-2-plus/index.php Date last accessed: September 13, 2019. Date last updated: June 15, 2017.

19 World Organization of Family Doctors (WONCA) International Classification Committee (WICC), International Classification of Primary Care. 2nd Edn (ICPC-2). Oxford, Oxford University Press, 1998.

20 Family Medicine Research Centre TUoS. CAPS - Coding Atlas for Pharmaceutical Substances 2002-2019. https:// sydney.edu.au/medicine/fmrc/caps/index.php Date last accessed: September 13, 2019. Date last updated: August 24 2011.

21 World Health Organization. ICD-10: International Statistical Classification of Diseases and Related Health Problems: tenth revision. Germany, German Institute of Medical Documentation and Information (DIMDI), 2004.

22 The Royal College of Anaesthetists. Dose Equivalent and Changing Opioids. www.rcoa.ac.uk/faculty-of-painmedicine/opioids-aware/structured-approach-to-prescribing/dose-equivalents-and-changing-opioids Date last accessed: September 13, 2019.

23 Australian Bureau of Statistics. Census of Population and Housing: Socio-Economic Indexes for Areas (SEIFA), Australia, 2011. Canberra, ACT, Commonwealth of Australia, 2013.

24 Australian Bureau of Statistics. Australian Statistical Geography Standard (ASGS). Canberra, ACT, Commonwealth of Australia, 2018

25 Vozoris NT, Wang X, Fischer HD, et al. Incident opioid drug use and adverse respiratory outcomes among older adults with COPD. Eur Respir J 2016; 48: 683-693.

26 Mitchell GK, Senior HE, Johnson CE, et al. Yates PM systematic review of general practice end-of-life symptom control. BMJ Support Palliat Care 2018; 8: 411-420.

27 Jennings AL, Davies AN, Higgins JPT, et al. A systematic review of the use of opioids in the management of dyspnoea. Thorax 2002; 57: 939-944.

28 Therapeutic Goods Administration. Kapanol ${ }^{\circ}$ (Morphine Sulfate Pentahydrate) Capsules, Dept. of Health, Editor. Commonwealth of Australia, 2019.

29 Rogers KD, Kemp A, McLachlan AJ, et al. Adverse selection? A multi-dimensional profile of people dispensed opioid analgesics for persistent non-cancer pain. PLoS ONE 2013; 8: e80095.

30 Bajwah S, Ross JR, Peacock JL, et al. Interventions to improve symptoms and quality of life of patients with fibrotic interstitial lung disease: a systematic review of the literature. Thorax 2013; 68: 867-879.

31 Bausewein C, Booth S, Gysels M, et al. Non-pharmacological interventions for breathlessness in advanced stages of malignant and non-malignant diseases. Cochrane Database Syst Rev 2008: CD005623.

32 Gysels M, Bausewein C, Higginson IJ. Experiences of breathlessness: a systematic review of the qualitative literature. Palliat Support Care 2007; 5: 281-302.

33 Hutchinson A, Barclay-Klingle N, Galvin K, et al. Living with breathlessness: a systematic literature review and qualitative synthesis. Eur Respir J 2018; 51: 1701477.

34 Carette H, Zysman M, Morelot-Panzini C, et al. Chabot F; Initiatives BPCO (bronchopneumopathie chronique obstructive) Scientific Committee and Investigators. Prevalence and management of chronic breathlessness in COPD in a tertiary care center. BMC Pulm Med 2019; 19: 95.

35 Ahmadi Z, Bernelid E, Currow DC, et al. Prescription of opioids for breathlessness in end-Stage COPD: a national population-based study. Int J Chron Obstruct Pulmon Dis 2016; 11: 2651-2657. 